\title{
Danza en tiempos de pandemia: Cuestionamientos y motivaciones de cuerpos en movimiento
} Dance in times of Pandemics: Questions and Motivations of Moving Bodies

Dança em tempos de pandemia: Questionamento e motivação de corpos em movimento

\section{Alexandra Delgado-Esquivel \\ Estudiante}

Escuela de Danza Contemporánea

Universidad Nacional

Costa Rica

Recibido: 25/08/2020 - Aceptado: 01/09/2020

\begin{abstract}
Resumen
Este ensayo brinda una reflexión sobre la danza y el cómo el distanciamiento físico y la adaptación a modalidades virtuales atraviesan el quehacer artístico partiendo de un inesperado contexto, la búsqueda de nuevos escenarios, las problematizaciones de los procesos de enseñanza/aprendizaje y las reflexiones en modo de resistencia y nuevas construcciones de los cuerpos en movimiento, sus entornos y realidades diversas.
\end{abstract}

Palabras claves: Danza, pandemia, distanciamiento, cuerpos, conexiones, Arte en América Latina

Abstract

This essay offers a reflection on dance and the way in which physical distancing and adaptation to virtual modalities crosses

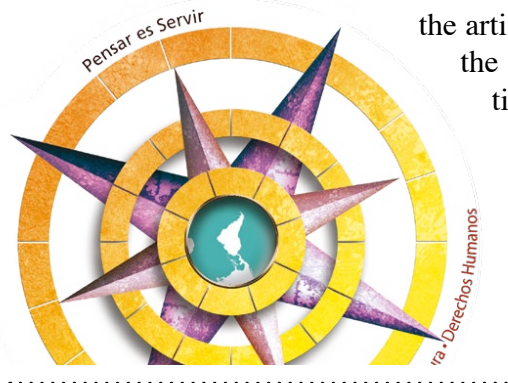
the search for new scenarios, the problematization of the teaching/learning processes and the reflections in resistance mode and new constructions of the bodies in movement, their environments and diverse realities 
Keywords: dance, pandemics, distancing, bodies, connections, Arts in Latin America

\section{Resumo}

Este ensaio oferece uma reflexão sobre a dança e como o distanciamento físico e a adaptação às modalidades virtuais cruzam o trabalho artístico a partir de um contexto inesperado, a procura de novos cenários, a problematização dos processos de ensino/aprendizagem e as reflexões em modo de resistência e novas construções dos corpos em movimento, dos seus ambientes e das suas diversas realidades

Palavras chave: dança, pandemia, distanciação, corpos, conexões, Arte na América Latina-

\section{Empezamos en la incertidumbre}

Desde siempre la danza ha significado contacto, comunicación, diálogos entre espacio y tiempo; se encuentra en diversidades de contextos que se mueven colectivamente, alimentando la inspiración del movimiento a través del compartir. Pero, ¿qué pasa cuando el distanciamiento físico rompe con el concepto vivencial de la danza que se reconocía hasta ahora?

Sin duda, nos atraviesa como colectivo artístico un contexto ante el cual se podría asumir que ninguna persona estaba preparada, porque se presentan nuevos retos que exigen desestructuraciones y luchas importantes ante una realidad poco empática y desfavorable para el ser artista.

Resulta necesario señalar que, si antes de la pandemia la situación socioeconómica de la comunidad artística resultaba crítica, ahora nos encontramos en condiciones preocupantes y de sobrevivencia.

Es así cómo, al observar las dinámicas de aprendizaje, enseñanza, encuentros, exploraciones y propuestas desde la danza, se reconoce, como se plantea anteriormente, que ninguna persona artista estaba preparada para sobrevivir en un contexto que intenta respirar desde una pantalla. Cambios de rutinas, espacios, posibilidades, oportunidades, necesidades técnicas y expresividades proponen un reto diario para la comunidad artística, pues el constante estado de adaptabilidad exige amoldarnos a lo desconocido y a la creatividad desesperada desde nuevas búsquedas para el ejercicio artístico.

¿Cuáles son nuestras principales necesidades?, ¿cuáles son nuestras

88 Danza en tiempos de pandemia: Cuestionamientos y motivaciones de cuerpos en movimiento Alexandra Delgado-Esquivel

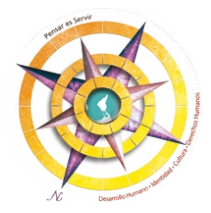


posibilidades colectivas de acción?, ¿qué sucede con el contexto que no nos permite ejercer desde lo que hemos construido a lo largo de los años?, ¿con cuáles recursos contamos? Surgen muchas preguntas sin respuesta, que ojalá motiven a la búsqueda para transformar la incertidumbre en acción colectiva.

\section{¿Entonces? Los escenarios cambian}

No es factible conceptualizar, de la misma manera, lo que en el ámbito del imaginario hemos construido como escenario, porque las redes sociales y las plataformas digitales/ virtuales abrazan al colectivo, significando una catapulta y espacio para socializar de proyectos, obras, servicios profesionales y otras propuestas, pues como artistas vivimos del compartir, del diálogo y de la retroalimentación de lo que tradicionalmente se podría considerar público y tradicional, porque no resulta viable para la comunidad artística pensarse desligada de la conexión con el público espectador, pues este es quien construye, consume, participa y, en gran parte, le da vida a nuestras propuestas. Por ello, la danza no se puede distanciar en su totalidad.

Como respuesta, hemos trasladado los teatros a nuestras casas, las tablas se han transformado en resignificaciones del espacio que habitamos, las clases existen en aparatos tecnológicos, viajan hasta las diferentes poblaciones y los encuentros artísticos están a un click de distancia. Entonces, se expande una gran incógnita: ¿cómo el distanciamiento atraviesa nuestra vivencia como artistas y nos condiciona a la búsqueda de nuevas posibilidades?

Por lo anterior, es importante cuestionar esta estructura privilegiada y tradicional de la percepción que podríamos construir de la danza desde un movimiento encerrado en salones de madera, espejos, escenarios con grandes dimensiones y luces, mientras que otras personas artistas no cuentan con estas facilidades y lujos. Es claro que hay falta de espacios y recursos para la práctica dancística en Costa Rica, sin duda la compañía de otros cuerpos nos acerca y aporta en nuestros procesos de aprendizaje, sin embargo, nos vamos percatando de que, para movernos, los teatros no resultan tan necesarios (Oliva y De La O, 2020).

Los escenarios se transforman y, al mismo tiempo, las visiones tradicionales de la danza que se encierra en cuatro paredes, también. Hay danza en las calles, en espacios en los que posiblemente nunca existiría el 
movimiento, escenarios impensables; prácticas más íntimas y personales, por lo que cambia la percepción y se genera cuestionamiento.

Nos reconocemos vulnerables ante un contexto que nos reta, pero encontramos alternativas en nuestro entorno. Estamos bailando más que nunca, desde otro lugar, claro, pero nos estamos moviendo ante alternativas.

\section{La crisis del estudiar y enseñar danza desde la virtualidad}

Es claro que los ajustes necesarios ante el distanciamiento físico involucran grandes cambios en las dinámicas de enseñanza/aprendizaje de las danzas, pues estas, sin previo aviso, requieren modificaciones inmediatas.

Primero, apuntando que, las clases de danza siempre han representado espacios de compartir, dispersión y cierto escape a la cotidianeidad, al verse atravesadas por el distanciamiento físico y las posibilidades de acceso a conexión o aparatos tecnológicos, resuena como un reto para la población estudiantil y, claro, para sus docentes, pues ninguna de estas personas participantes estaba preparada para enfrentar a nivel pedagógico lo que resignifican las clases virtuales de danza y los cambios significativos en nuestras rutinas (Lerma, 2020).

Aun así, más allá de si la dinámica virtual funciona o no para estudiar o practicar danza, como estudiantes y docentes nos enfrentamos a condiciones poco funcionales para el ejercicio, posibles ambientes que no colaboran para un proceso disfrutable, sano y consciente.

Por tanto, más que nunca, la reflexión que cada artista en formación se haga sobre este proceso y las prioridades, acciones, responsabilidades y trabajo consciente, al respecto, es sumamente necesario.

En docentes y estudiantes, la empatía, la sensibilidad y la escucha son necesarias, pues si bien nos estamos formando como profesionales o ejerciendo prácticas para las cuales nos hemos formado, atravesamos un contexto que, en muchas ocasiones, nos resulta insostenible porque surgen otras prioridades que impactan aún más las condiciones socioemocionales.

Por tanto, desde ambas experiencias (docente/estudiante) la comunicación, construcción horizontal y colectiva son fundamentales para sostener una dinámica pesada, donde requerimos constante aprendizaje y

90 Danza en tiempos de pandemia: Cuestionamientos y motivaciones de cuerpos en movimiento Alexandra Delgado-Esquivel

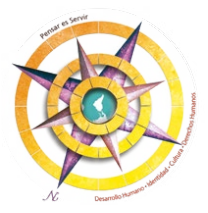


cuestionamiento desde nuestras posibilidades, recursos, necesidades $\mathrm{y}$, claro, procesos de formación artística.

\section{Lo que estamos aprendiendo}

En agradecimiento al contexto actual, pues no solamente existe un lado gris, nacen algunas propuestas que responden a las necesidades de la comunidad artística, por mencionar algunas: Proxemia, una plataforma para la apertura de clases virtuales de danza, música, cocina, bordado y otras especialidades; y En Las Casas, un espacio vía live streaming de espectáculos de danza y otras iniciativas desde Danza Universitaria, festivales significativos transformados a la virtualidad y artistas o colectivos independientes que buscan responder a una realidad que invita a mantener la danza o el arte escénico latiendo en la cotidianeidad.

A partir de las diversas posibilidades de (des)conexiones existentes del entorno actual, las personas artistas nos adaptamos al tener que mirarnos más de lo experimentado, buscar esa danza o movimiento personal, dentro de una sensación de soledad acompañada, reconocerse en una danza que no tiene cuerpos danzantes cerca, sino que dialoga con sí misma. Encontramos que nos estamos moviendo desde otro lugar, uno que antes solía ser muy cotidiano, pero desconocido: uno en proceso de reconocimiento y resignificación.

A su vez, las modalidades que atraviesan la danza en estos días han permitido mayor profundización en quizás uno de los vacíos más problematizados en el ámbito artístico, los cuales están ligados a la investigación y producción teórica dentro de la danza: el distanciamiento físico y las medidas urgentes de adaptabilidad y construcción de iniciativas, invita a que la danza se acomode en su escritorio y escriba, lea, conceptualice y, así, nutra su desarrollo práctico, experiencia necesaria para el crecimiento de las disciplinas y las no disciplinas.

\section{A modo de reflexión: Resistimos}

En esta reflexión resuena mi propia realidad, en ideas que de alguna forma nacen de la especificidad de mi entorno, en la búsqueda de motivar diálogos, ya que como artista en formación me atraviesa un contexto desconocido.

La danza en tiempos de pandemia ha permitido el involucramiento de mi familia en la formación universitaria que atravieso, pues nunca habría podido involucrar a mi familia en mi 
carrera de tal manera, pues existe una dimensión más reconocible de lo que hacemos, me observan, apoyan, están en clases, porque compartimos un espacio y viven junto a mí este proceso, lo cual agradezco en cuanto a las problemáticas que atravesamos como artistas a la hora de decidir estudiar una carrera artística y lo complejo que puede resultar describir lo que hacemos o vincular a nuestras familias.

Además, agradezco que el contexto me ha permitido cuestionar el porqué de mi movimiento o el porqué de mis necesidades expresivas. Se resta prioridad a las exigencias técnicas y se brinda protagonismo a proyectos comunitarios, talleres, conversatorios, propuestas creativas, inclusive se prioriza mi salud, deseos y metas que acompañan la realidad actual de manera crítica. Sin duda, cuestiono el rol que asumo como artista y los recursos con los que cuento para construir tejidos diversos de acción, creación y movimiento.

Entiendo que, aunque somos cuerpos lejanos en distancia kilométrica, resistimos en conexión de sentires, con cuerpos que extrañan y luchan por adaptarse para seguir moviéndonos.

Los escenarios no están vacíos, se mudaron más cerca, están en nuestros cuartos, patios y salas, las maestras y maestros de danza no están en la pantalla, están resonando en nuestros cuerpos, quienes nos acompañan en nuestros procesos de formación o caminos independientes están en busca de nuevas direcciones, la conexión se transforma y se fortalece cuando nos movemos pensando en la compañía más allá de lo físico.

A manera de promover un cierre, resulta necesario apuntar que para Patricia Oliva y Vanessa De La O (2020), el tiempo de danza en pandemia se apalabra desde la resistencia y cuestionamiento colectivo, pues para estas artistas:

Practicar danza, moverse, puede ser mucho más cotidiano y accesible de lo que podemos pensar y justamente esta crisis nos recuerda que la práctica artística, que quizá hemos ubicado en último lugar, está más cerca de lo que pensamos. ... Quizá sea este el momento de escuchar al cuerpo. Este momento de pausa y silencio puede convertirse en una oportunidad para observar-se, percibir-se en un cuerpo agotado y triste por la rutina. (pp. 41 y 43)

Sin ánimos de romantizar nuestra realidad como personas artistas o idealizar nuestras prácticas creativas, nos encontramos en un proceso de histórico que nos determina,

92 Danza en tiempos de pandemia: Cuestionamientos y motivaciones de cuerpos en movimiento Alexandra Delgado-Esquivel

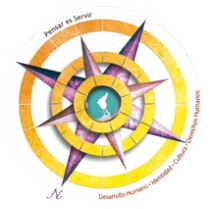


limita, afecta e impacta; pero también nos enseña que la danza no se distancia; la danza nace a cada segundo; la danza nos conecta porque nos recuerda; la danza existe porque le damos vida, la transformamos, cuestionamos y contextualizamos a cada paso; pero, sobre todo, la hacemos nuestra y la reconceptualizamos desde la resistencia de lo que significa ser artista del movimiento, en un mundo que se percibe tan pausado.

\section{Referencias}

Lerma, I. (2020). El profesor de danza y el uso de las TIC en tiempos de contingencia. Revista Latinoamericana de Estudios Educativos, 50(ESPECIAL), 303-312. https://rlee.ibero. $\mathrm{mx} / \mathrm{index} . \mathrm{php} / \mathrm{rlee} / \mathrm{article} / \mathrm{view} / 115 / 488$

Oliva, P., \& De La O Jiménez, V. (2020). Arte, cuerpo y movimiento a ritmo de COVID: Preguntas sobre la danza desde el encierro. Revista Rupturas, 10, 39-43. https://revistas. uned.ac.cr/index.php/rupturas/article/view/2922 
